\title{
Cellular mechanisms of acute lung injury: implications for future treatment in the adult respiratory distress syndrome
}

The adult respiratory distress syndrome is a catastrophic form of lung injury. When originally described by Ashbaugh and his coworkers in 1967 it had an associated mortality approaching $70 \% .{ }^{1}$ Over the intervening 20 years progress in developing specific treatment for it has been disappointing; treatment is in the main supportive and mortality remains at $50-70 \% .^{2}$ The syndrome classically arises after a "latent" period of 24-72 hours following one of the varied insults that may provoke it (the most frequent being multiple trauma, septicaemia, and pancreatitis). Despite the multiplicity of initial predisposing causes, the pathological findings, by the time the patients present with lung disease, are remarkably uniform. In addition to the early histological findings of acute lung inflammation, with leakage of fluid and protein into the interstitium and airspaces, there is also evidence of type II epithelial cell and fibroblast proliferation, and even early deposition of "scar tissue" matrix proteins. This common picture suggests that a shared pathological process may operate in the early stages of most cases of adult respiratory distress syndrome regardless of the precipitating cause. Recent advances in cellular and molecular biological techniques are likely to offer new opportunities for fine dissection of the pathogenesis of adult respiratory distress syndrome in the early stages. This may lead to the identification of more accurate predictors of very high risk for the full blown clinical adult respiratory distress syndrome, and the latent period may also provide a "window of opportunity" whereby specific mechanism based treatments introduced early for patients at very high risk might be expected to attenuate the severity of lung injury or even to abort the full blown syndrome. The present state of knowledge of the early pathogenesis of the adult respiratory distress syndrome points to a complex interplay between humoral mediators released by the initiating condition and the damaging effects of injurious products released from inflammatory cells on the endothelial and epithelial cells of pulmonary microvessels.

\section{Neutrophils and the adult respiratory distress syndrome}

The neutrophil is the archetypical acute inflammatory cell. It contains various potentially histotoxic agents (table 1), many of which have been specifically implicated in inflammatory diseases. ${ }^{3}$ The neutrophil has been implicated in animal models of acute lung injury induced by circulating endotoxin, ${ }^{4}$ hyperoxia, ${ }^{5}$ and microembolisation ${ }^{6}$; and investigation of bronchoalveolar lavage fluid from patients with the established adult respiratory distress syndrome has shown excess numbers of neutrophils ${ }^{7}$ and excessive amounts of their potentially injurious agents, such as the

Table 1 Potentially histotoxic neutrophil products

\begin{tabular}{ll}
\hline Oxidants and radicals & Proteolytic enzymes \\
Superoxide anion & Elastase \\
Hydrogen peroxide & Gelatinase \\
Hydroxyl radical & Collagenase \\
Hypochlorous acid & Cathepsin \\
Chloramines & Lysozyme \\
Nitric acid & Neuraminidase \\
& Heparanase
\end{tabular}

Others

Cationic proteins protease enzymes elastase ${ }^{7}$ and collagenase. ${ }^{8}$ These enzymes and hydrogen peroxide found in expired air from patients with the adult respiratory distress syndrome having assisted ventilation ${ }^{9}$ are thought to derive from activated inflammatory cells within injured lungs. Much evidence points to a role for the neutrophil in the development of the adult respiratory distress syndrome, though it is well recognised that the syndrome may occur in neutrophil depleted patients. ${ }^{10}$ These examples may represent a distinct subgroup within the spectrum of the adult respiratory distress syndrome, or they may reflect the part played by other inflammatory cells with a destructive potential similar to that of the neutrophil (for example, cells of the monocyte-macrophage series). Nevertheless, the neutrophil granulocyte is likely to have an important role in the adult respiratory distress syndrome associated with the most common predisposing conditions, and this article will focus on the neutrophil as exemplifying the archetypical acute inflammatory cell.

The lung normally contains a "marginated pool" of neutrophils that is in a state of dynamic equilibrium with the circulating pool. This localisation of potentially destructive cells may explain in part why the lung is at particular risk of injury triggered by systemic or distant insults in the early pathogenesis of the adult respiratory distress syndrome. Diseased lungs-for example, in chronic obstructive pulmonary disease ${ }^{11}$ - have an increased neutrophil burden within the pulmonary vasculature, representing enhanced potential for neutrophil mediated lung damage. It is also clear, however, that excessive neutrophil sequestration in the lung does not necessarily cause lung injury ${ }^{12}$ and several other factors, such as the state of activation, the secretory state, and the type and degree of contact between the neutrophils and pulmonary microvascular endothelial cells, must also contribute. In the remainder of this article we will focus on the mediators that are likely to have an important action on neutrophils, the concept of a pericellular microenvironment favouring neutrophil mediated endothelial injury, and the neutrophil products that are likely to be particularly important in causing tissue injury.

\section{MEDIATORS}

Many mediators have been implicated in the pathogenesis of the adult respiratory distress syndrome yet the search for a single common final mediator for the disease process has so far been disappointing. The disease process is more likely to be provoked by a complex interplay between several important mediators, including the complement cleavage product $\mathrm{C} 5 \mathrm{a}$, tumour necrosis factor, platelet activating factor, leukotriene B4, interleukin 8 , and endotoxin. Not all of these mediators have identical effects on inflammatory cells. Some, including C5a, leukotiene B4, and interleukin 8, are capable of stimulating neutrophils to secrete large quantities of potentially injurious agents (secretagogues). Others, such as bacterial lipopolysaccharide, tumour necrosis factor, and platelet activating factor, though not very effective at low concentrations in causing neutrophil secretion, may "prime" neutrophils so that they release enhanced quantities of potentially injurious agents when subsequently exposed to secretagogues or triggering agents. Acute lung injury has been produced in experimental animals after the intravenous administration of a combination of small amounts of 


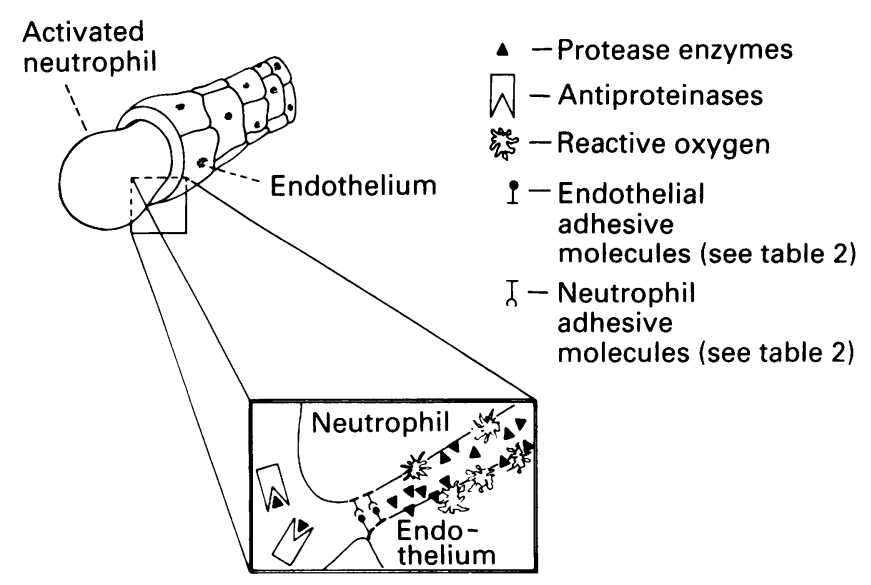

Figure 1 Concept of a restricted pericellular microenvironment favouring tissue injury at the neutrophil-endothelial interface.

bacterial lipopolysaccharide (an effective primer) and C5a (an effective secretagogue), both of which have been implicated in the adult respiratory distress syndrome, but not with either agent alone. ${ }^{13}$ Similar results have been obtained with neutrophil mediated endothelial injury in vitro. ${ }^{14}$ Thus we may reasonably propose that amplification mechanisms, based on the initial action of priming agents followed by the action of secretagogues, combine to enhance the potential for tissue injury in the early adult respiratory distress syndrome. Priming agents, such as bacterial lipopolysaccharide, have been shown to influence some other neutrophil functions, which could also tilt the balance of the inflammatory process towards tissue injury. These processes include increase in neutrophil adhesiveness, reduction of neutrophil chemotaxis, ${ }^{15}{ }^{16}$ and reduction of neutrophil deformability. ${ }^{17}$ These effects are likely to help to increase the time of contact between actively secreting neutrophils and endothelial cells within the pulmonary microcirculation, thus enhancing the potential for tissue injury.

\section{CONCEPT OF A MICROENVIRONMENT FAVOURING TISSUE INJURY}

Neutrophil mediated endothelial injury does not occur in vitro without direct neutrophil adherence. The observation that neutrophil mediated degradation of the matrix still occurs in the presence of antiproteinase ${ }^{18}$ has led to the concept of a restricted pericellular microenvironment serving to create a local environment between neutrophils and endothelial cells that may favour microvascular injury by several possible mechanisms (fig 1). Firstly, the most toxic reactive oxygen intermediates are such reactive molecules that they are likely to exert an effect over only a short distance in tissues; secondly, large molecular weight antiproteinases, such as $\alpha_{1}$ protease inhibitor, would be excluded, permitting unopposed action of agents such as neutrophil elastase; and, finally, some neutrophil enzymes may attain high concentrations at the cell surface instead of being dissipated into the extracellular fluid. A microenvironment favouring injury is likely to be created by the combination of changes in cell deformability and the expression of intercellular adhesive molecules, both of which have recently been shown to be greatly influenced by some of the mediators considered above. The mean diameter of the neutrophil is about $7.0 \mu \mathrm{m}$ whereas that of the pulmonary capillary is $5.5 \mu \mathrm{m}$. Neutrophils must therefore deform in order to pass through a capillary. Neutrophil deformability is greatly reduced in activated states induced by $\mathrm{C} \mathrm{a}^{19}$ or bacterial lipopolysaccaride ${ }^{17}$ an effect that would reduce their ability to "squeeze" through lung capillaries and would increase their contact with microvascular endothelial cells. There is increasing evidence ${ }^{19}$ that alterations in neutrophil deformability have direct effects on their sequestration in the lung. ${ }^{20}$ Similarly, the adhesiveness of neutrophils and of endothelial cells is greaty amiplinea oy exposure to some of the inimamatory mediators. The addition of C5a or platelet activating factor to neutrophils enhances their adhesion to endothelial cells within minutes. ${ }^{21}$ As endothelial cells exposed to bacterial endotoxin may take several hours to increase expression of important adhesion molecules, such as the intercellular cell adhesion molecule-1 (ICAM-1) or the endothelial leucocyte adhesion molecule (ELAM-1), these are unlikely candidates for the earliest adhesive interactions with neutrophils. Recent evidence, however, suggests that granule membrane protein-140 (GMP-140), another endothelial adhesive molecuie, may be expressed very early after endothelial stimulation. The recent explosion of knowledge of neutrophil-endothelial adhesion ${ }^{22}$ may produce special therapeutic opportunities in patients at risk of the adult respiratory distress syndrome (see below), though we have not yet established which mechanisms are the most important or the relative importance of deformability and adhesive mechanisms in the early stages of the syndrome. In addition to the mechanism of neutrophil endothelial contact the dynamics of the interaction have to be considered, and also the amplification effects of further neutrophils released from the bone marrow, which are similarly exposed to modulating agents both systemically and within the pulmonary microvasculature. For example, an actively secreting neutrophil that remains in contact with an endothelial cell for several seconds is likely to have a more destructive potential than one in contact for only a few milliseconds. The combination of trace concentrations of bacterial lipopolysaccharide (a priming agent) and formyl-methionyl-leucyl-phenylalanine (FMLP, a secretagogue not only promotes neutrophil secretion but also exerts supra-adutitive effects on neutrophi adhesiveness in vitro ${ }^{25}$ and on neutrophil sequestration in the pulmonary vasculature, ${ }^{13}$ an effect that persists in vivo for several hours after the intravenous injection of the combination of these agents.

\section{POTENTIALLY INJURIOUS PRODUCTS}

Neutrophils contain more than 30 agents with proved capacity in the activated state to injure tissues; some of the more important ones are shown in table 1. Over the last few years the spotlight has focused on reactive oxygen intermediates as the most important primary agents in neutrophil mediated tissue injury. More recently, however, attention has moved to indirect actions of reactive oxygen intermediates, in particular secondary effects that might be exerted by their inactivation of aniprotetrases. Anr recent study of neutrophil mediated endothelial injury inhibitors and scavengers of reactive oxygen intermediates did not prevent neutrophil mediated endothelial injury, whereas the addition of a specific neutrophil elastase inhibitor alone attenuated injury. ${ }^{25}$ Neutrophil elastase has been found in increased quantities in the lavage fluid from patients with the adult respiratory distress syndrome. ${ }^{7}$ The cellular toxic mechanisms of this enzyme are uncertain; although its ability to digest elastin and other proteins as well as being highly cationic may be contributory mechanisms, other relevant effects may yet be elucidated. This enzyme is emerging as one of the primary candidates responsible for tissue injury in neutronhilmediated inflammatory diseases and the adult racpiratory distress syndrome in particưlar.

Within this framework we can now construct a likely sequence of events following the initial provoking condi- 
Mediators

(LPS, TNF, IL-8)

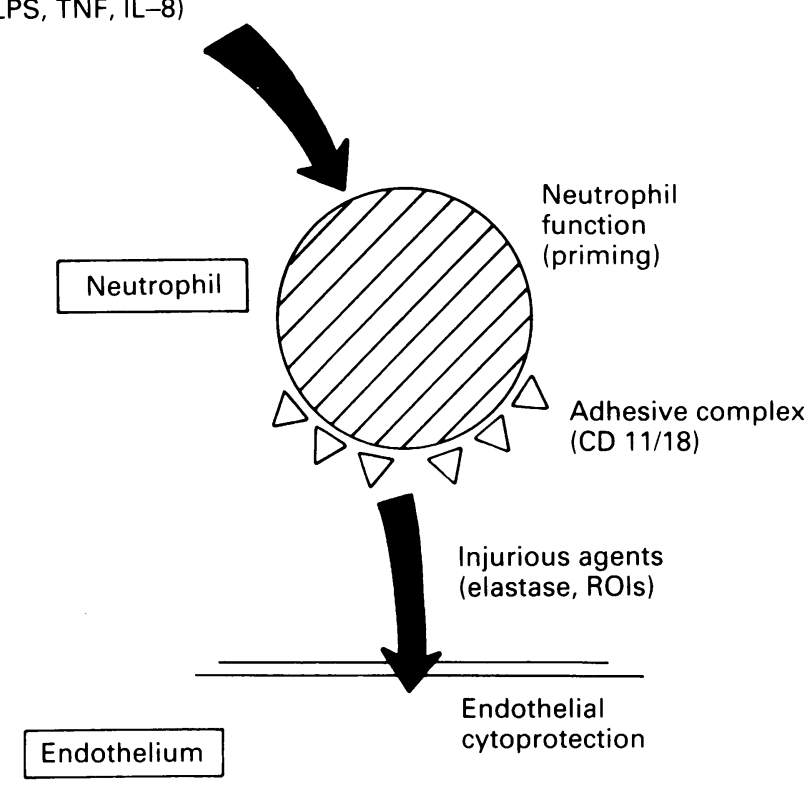

Figure 2 Potential "attack" points for therapeutic intervention. $R O I s$-reactive oxygen intermediates.

tion. In response to an often distant insult mediators are released that prime and trigger neutrophils and other inflammatory cells to secrete large amounts of histotoxic agents. These activated neutrophils are less deformable and express greatly increased numbers of adhesion receptors, thus increasing and prolonging contact with the endothelium and creating a restricted neutrophil-endothelial interface which provides a microenvironment favouring cell injury. Amplification of injury occurs by the accumulation of newly released bone marrow neutrophils, which also become primed, triggered, and sequestered in the lung. The subsequent endothelial and epithelial injury allows leak of protein rich exudate into the interstitium and alveolar spaces, leading to cytokine cascades and repeated epithelial injury, which may promote replication of fibroblasts and deposition of matrix.

These later stages of the adult respiratory distress syndrome are likely to have been reached by the time the patient presents with full blown lung disease, when it is difficult to conceive of any simple therapeutic approach. But the existence of a latent period betore the onset of lung disease in most cases and new knowledge of the likely early cellular and molecular events are likely to provide special opportunities for incisive treatment in patients at high risk of this catastrophic condition.

\section{Newer therapeutic strategies}

As yet there is no effective pharmacological therapy for the adult respiratory distress syndrome and treatment is supportive. Treatment with corticosteroids is controversial. High dose corticosteroids did not improve outcome in controlled clinical trials ${ }^{26}$ and may even be detrimental in cases of sepsis. Many agents have been investigated for a possible beneficial effect in the disease process. These include cyclo-oxygenase inhibitors (non-steroidal antiinflammatory agents such as lonazolac), ${ }^{27}$ oxygen scavenging agents, such as $\mathrm{N}$-acetylcysteine, ${ }^{28}$ and vasodilators, such as prostacyclin. ${ }^{29}$ Pentoxifylline, a methylated xanthine, has received particular attention recently because it has exerted a beneficial effect in several models of acute lung injury. ${ }^{3031}$ The reduction of pulmonary oedema formation induced by pentoxifylline might be due to its antiinflammatory effects on neutrophils, ${ }^{32}$ which may operate in several ways, including reduction of superoxide production $^{33}$ and increase in neutrophil filterability. ${ }^{34}$

Rational and safe therapeutic strategies, however, are likely to derive only from a detailed understanding of the cellular and molecular mechanisms of the early adult respiratory distress syndrome. The interactions between inflammatory cells (neutrophils) and microvascular endothelial cells provide several potential "attack" points (fig 2).

MEDIATORS INFLUENCING INFLAMMATORY CELLS Although the mediators that influence inflammatory cells are probably numerous, bacterial lipopolysaccharide, tumour necrosis factor, and interleukin-8 are likely to be particularly important. Although such mediators are possibly generated too early after the provoking insult to be a useful target, they may also play a part later in important amplification events; there are suggestions that antiendotoxin antibodies may have been protective in some (but not all) studies of sepsis. ${ }^{35}$

\section{ABNORMAL NEUTROPHIL SEQUESTRATION}

The molecular identification of specific intercellular adhesive processes is likely to provide special opportunities for disrupting intercellular microenvironments that favour injury. Monoclonal antibodies against molecules of the leucocyte integrins, selectins, and the immunoglobulin supergene family are avaitate (tavie 2 ). These, however, are also likely topreventmoutraphil migration in support of host defence in other organs, which in patients with trauma and sepsis are particularly susceptible to secondary infection.

\section{INJURIOUS INFLAMMATORY CELL PRODUCTS}

Development of treatments directed against injurious inflammatory cell products have been hampered by our awareness of the multiplicity of neutrophil products with the potential to injure tissues, plus our uncertainty about which of the many agents are likely to be particularly important clinically. Many of the agents produced so far have been rather non-specific in their action or too toxic for clinical use. Nevertheless, neutrophil elastase is assuming prominence as a neutrophil product of great importance in several inflammatory diseases and considerable effort is likely to be made by the pharmaceutical industry in identifying safe and specific inhibitors of this enzyme.

\section{CELLULAR DEFENCES}

Endothelial cells appear to tolerate a certain degree of proteinase or oxidative load without irreversible damage,

Table 2 Adhesive molecules and ligands relevant to neutrophilendothelial interactions

\begin{tabular}{|c|c|c|}
\hline $\begin{array}{l}\text { Cell type and } \\
\text { workshop cluster } \\
\text { designation }\end{array}$ & $\begin{array}{l}\text { Common } \\
\text { nomenclature }\end{array}$ & Ligands \\
\hline \multicolumn{3}{|l|}{ Neutrophil } \\
\hline CD11a/CD18 & LFA-1 & $\begin{array}{l}\text { ICAM-1 } \\
\text { ICAM-2 }\end{array}$ \\
\hline $\mathrm{CD} 11 \mathrm{~b} / \mathrm{CD} 18$ & CR3 & $\begin{array}{l}\text { C3bi } \\
\text { ICAM-1 } \\
\text { Fibrinogen }\end{array}$ \\
\hline CD11c/CD18 & $P 150,95$ & $\begin{array}{l}\text { C3bi? } \\
\text { Endothelial ligand } \\
\text { Fibrinogen }\end{array}$ \\
\hline $\mathrm{W} / \mathrm{D}$ & $\begin{array}{l}\text { LAM-1 (MEL-14 } \\
\text { Mouse) }\end{array}$ & $\begin{array}{l}\text { Endothelial carbohydrate } \\
\text { molecule }\end{array}$ \\
\hline \multicolumn{3}{|l|}{ Endothelium } \\
\hline CD62 & $\begin{array}{l}\text { GMP-140 Padgem } \\
\text { ELAM-1 }\end{array}$ & $\begin{array}{l}\text { Sialylated Lewis } \times \\
\text { antigen (CD15 on } \\
\text { neutrophil) }\end{array}$ \\
\hline
\end{tabular}


yet very little is known about the protective mechanisms. Other cytoprotective systems (for example, in paracetamol induced nepatocyte toxicity) are better understood, and elucidation of endothelial cytoprotective mechanismsagainst neutrophil elastase, for example-should provide opportunities for boosting such mechanisms and thereby attenuating microvascular injury.

There are many strands in the web of the inflammatory response, and removal of a single strand is unlikely to inhibit progression of the disease process. Inhibition of two or three key events early in the inflammatory process would be more likely to attenuate the disease. Although the above strategies represent exciting future therapeutic options, overzealousness should be tempered by our knowledge that the destructive elements of the inflammatory response may also, paradoxically, be important in host defence. Major progress is likely to be made by fine dissection of injurious mechanisms to distinguish these from beneficial processes, and by more clearly defining the temporal stages of inflammatory disease in the hope of identifying a stage or stages when a particular cell or process is more critical to the disease process than it is to host defence.

\section{SC DONNELLY}

C HASLETT

\section{Respiratory Medicine Unit,
City Hospital,}

Edinburgh EH10 $5 S B$

Reprint requests to: Professor C Haslett

$Q_{1}$ Ashbaugh DG, Bigelow DB, Petty TL, Levine BE. Acute respiratory distress in adults. Lancet 1967;ii:319-23.

2. Rocker GM, Wiseman MS, Pearson D, Shale DJ. Diagnostic criteria for adult respiratory distress syndrome time for reappraisal. Lancet 1989;i:120-3.

3 Haslett C, Savill JS, Meagher L. The neutrophil. Curr Opin Immunol 1989;2:10-8.

4 Brigham KL, Bowers $\mathrm{R}$, Haynes J. Increased sheep lung vascular permeability caused by $E$ coli endotoxin. Circ Res 1979;45:292-7.

5 Shasby DM, Fox RB, Harada RN, Repine JE. Reduction of the oedema of acute hyperoxic lung injury by granulocyte depletion. J Appl Physiol 1982;52:1237-44.

6 Johnson A, Malik AB. Effect of granulocytopenia on extravascular lung water content after microembolization. Am Rev Respir Dis 1980;122: 561-6.

7 Dee CT, Fein AM, Lippman M, Hotzmann H, Kimbel P, Weinbaum G. Elastolytic activity in pulmonary lavage fluid from patients with adult respiratory distress syndrome. N Engl J Med 1981;304:192-6.

8 hristner P, Fein A, Goldberg S, et al. Collagenase in the lower respiratory tract of patients with adult respiratory distress syndrome. Am Rev Resp Dis 1985;131:690-5.

9 Baldwin SR, Grum CM, Boxer LA, Simon RH, Ketai LH, Devall LJ. Oxidant activity in expired breath of patients with adult respiratory distress syndrome. Lancet 1986;i:11-3.

10 Braude S, Apperley J, Krautz T, Goldman JM. Adult respiratory distress syndrome after allogenic bone-marrow transplantation, evidence for a neutrophil-independent mechanism. Lancet 1985;i:1239-42.

11 Selby C, Drost E, Lannan S, Wraith PK, MacNee W. Neutrophil retention in the lungs of patients with chronic obstructive pulmonary disease. $\mathrm{Am}$ Rev Respir Dis 1991;143:1359-64.

12 Haslett C, Worthen GS, Giclas PA, Morrison DC, Henson JE, Henson PM.
The pulmonary vascular sequestration of neutrophils in endotoxaemia is initiated by an effect of endotoxin on the neutrophil in the rabbit. $A m R e v$ Respir Dis 1987;136:9-18.

13 Worthen GS, Haslett C, Rees AJ, Gumbay RS, Henson JC, Henson PM Neutrophil-mediated pulmonary vascular injury. Synergistic effects of trace amounts of lipopolysaccharide in $\mathrm{C} 5 \mathrm{a}$-induced lung injury. Am $\mathrm{Rev}$ Respir Dis 1987;136:19-28.

14 Smedley LA, Tonnesen MG, Sanhaus RA, Haslett C, Guthrie LA, Johnson $\mathrm{RB}$, et al. Neutrophil mediated injury to endothelial cells: enhancement by
endotoxin and essential role of neutrophil elastase. J Clin Invest endotoxin and

15 Haslett C, Guthrie LA, Kopaniak MM, Johnston RB, Henson PM Modulation of multiple neutrophil functions by preparative methods or trace concentrations of lipopolysaccharide. Am J Pathol 1985;119:101-10.

16 Dahinden C, Galanos C, Fehr J. Granulocyte activation by endotoxin. $J$ Immunol 1983;130:857-61.

17 Erzurum SC, Downey GP, Worthen GS. Bacterial lipopolysaccharide mediates microfilament-dependent retention of neutrophils in mode capillaries [abstract]. Am Rev Respir Dis 1989;139:A298.

18 Cambell ET, Senior RM, McDonald JA, Cox DL. Proteolysis by neutrophils. Relative importance of cell-substrate contact and oxidative inactivation of proteinase inhibitors in vitro. J Clin Invest 1982;70:845-52.

19 Worthen GS, Schwab B, Elson EL, Downey GP. Mechanisms of stimulated neutrophils: cell stiffening induces retention in capillaries. Science 1989;245:183-5.

20 Selby $\mathrm{C}$, Drost $\mathrm{E}$, Wraith $\mathrm{PK}, \mathrm{MacNee} \mathrm{W}$. In vivo neutrophil sequestration within the lungs of man is determined by in vitro "filterability". $J A p p l$ Phys 1991;71:1996-2003.

21 Tonnesen MG, Smedly LA, Henson PM. Neutrophil-endothelial cell interactions. Modulation of neutrophil adhesiveness induced by the complement components C5a and C5a des arg and formyl-methionylleucyl-phenylalanine in vitro. J Clin Invest 1984;74:1581-92.

22 Springer TA. Adhesion receptors of the immune system. Nature 1990;346:425-34.

23 Young SK, Worthen GS, Haslett C, Tonnesen MG, Henson PM. Interaction between chemoattractants and bacterial lipopolysaccharide in the induction and enhancement of neutrophil adhesion. Am J Respir Cell Mol Biol 1990;2:523-32.

24 Weiss SJ. Tissue destruction by neutrophils. $N$ Engl J Med 1989;320: 365-76.

25 Smedley LA, Tonneson MG, Sandhaus RA, Haslett C, Guthrie LA, Johnston RB, et al. Neutrophil-mediated injury to endothelial cells: enhancement by endotoxin and essential role of neutrophil elastase. J Clin Invest 1986;77:1233-43.

27 Bernard GR, Luce JM, Sprung CL, et al. High dose corticosteroids in patients with the adult respiratory distress syndrome. $N$ Engl J Med 1987;317:1565-70.

27 Van Velzen C, de Rutter HA, Lachmann B. Lonazolac a useful comedication in treatment of ARDS? [abstract]. Intens Care Med 1990; 16:A108.

28 Hanique G, Rosselee J, Reynaert M. A prospective randomized study of $\mathrm{N}$ acetylcysteine in the treatment of adult respiratory distress syndrome [abstract]. Intens Care Med 1990;16:A109.

29 Radermacher P, Santak B, Wust HJ, Tarnow J, Falke KJ. Beneficial effects of prostacyclin for the treatment of pulmonary hypertension associated with ARDS [abstract]. Intens Care Med 1990;16:A127.

30 Ishizaka A, Wu Z, Stephens KE, et al. Attenuation of acute lung injury in septic guinea pigs by pentoxifylline. Am Rev Respir Dis 1988;138:376-82.

1 Welsh CH, Lien D, Worthen GS, Weil JV. Pentoxifylline decreases endotoxin-induced pulmonary neutrophil sequestration and extravascular protein accumulation in the dog. Am Rev Respir Dis 1988;138:1106-14.

32 Seear MD, Hannam VL, Kaapa P, Usha Raj J, O'Brodovich HM. Effect of Pentoxifylline on haemodynamics, alveolar fluid reabsorption and pulmonary oedema in a model of acute lung injury. Am Rev Respir Dis 1990;142:1083-7.

33 Mandell GL. ARDS, neutrophils and pentoxifylline. Am Rev Respir Dis 1988;138:1103-5.

34 Schmalzer EA, Chien S. Filterability of subpopulation of leukocytes: effects of Pentoxifylline. Blood 1984;64:542-4.

35 Ziegler EJ, Fisher CJ, Sprung CL, Straube RC, Sadoff JC, Foulke GE, et al. Treatment of gram negative shock with HAlA human monoclona antibody against endotoxin. $N$ Engl J Med 1991;324:429-36. 